\title{
Reply to comments on: McAuley KA, Hopkins CM, Smith KJ, McLay RT, Williams SM, Taylor RW, Mann JI (2005) Comparison of high-fat and high-protein diets with a high-carbohydrate diet in insulin-resistant obese women. Diabetologia 48:8-16
}

Published online: 26 May 2005

(C) Springer-Verlag 2005

To the Editor: We thank Drs Feinman and Volek for their interest in our study comparing high-fat and high-protein diets with high-carbohydrate diets in insulin-resistant women [1].

Both letters are concerned that we have underestimated the impact of our results and shown a bias against high-fat diets. However, we clearly stated that increased weight loss was observed in both the high-fat and the high-protein diets compared with the high-carbohydrate diet, and concluded that the high-fat diet is an effective short-term approach to weight loss. This does not enable one to endorse any 'diet' in the long term.

We did not find any significant difference in energy intake between the three groups using 3-day diet records. Due to the unreliability of energy intake values calculated from diet records, it would be unwise to conclude that

K. A. McAuley $(\bowtie) \cdot$ J. I. Mann

Edgar National Centre for Diabetes Research,

University of Otago,

Dunedin, New Zealand

e-mail: kirsten.mcauley@stonebow.otago.ac.nz

Tel.: +64-3-4798153

Fax: +64-3-4747641

J. I. Mann · R. W. Taylor

Department of Human Nutrition,

University of Otago,

Dunedin, New Zealand energy intakes were in fact similar across the three groups. We stressed the limitations of diet record data including under-reporting [1]. However, we did not state, as suggested by Feinman and Volek, that this applied to a greater extent to the high-fat groups than to the others. We have no way of measuring whether under-reporting was different between groups. We do not believe that diet record data are sufficiently reliable to make further calculations such as those suggested by Feinman (presented as energy lost). Furthermore, levels of significance were not given for the energy changes shown in Fig. 1 by Feinman. The differences shown in the Feinman graph, if calculated on a daily basis, show a difference between the diets of between 130 and $300 \mathrm{~kJ} / \mathrm{day}$. Such a difference is likely to be subject to a relatively wide margin of error.

We did not make 'excuses' for the high-carbohydrate group. We simply indicated what is evident in Table 1 of our paper, that despite the advice the patients received, this group did not achieve the desired high-fibre intake [1]. It would be interesting to compare weight loss in a highcarbohydrate, high-fibre diet with that in the high-fat and high-protein diets.

\section{References}

1. McAuley KA, Hopkins CM, Smith KJ et al (2005) Comparison of high-fat and high-protein diets with a high-carbohydrate diet in insulin-resistant obese women. Diabetologia 48:8-16 